\title{
SOBRE LA GENERALIDAD DEL YEÍSMO PORTEÑO EN EL SIGLO XIX
}

La distinguida estudiosa María Beatriz Fontanella de Weinberg, a quien tanto deben los estudios sobre el español de la Argentina, ha avanzado recientemente una tesis novedosa sobre la historia del yeísmo en Buenos Aires; según ella, durante el siglo pasado habrían coexistido en el habla porteña formas rehiladas y no rehiladas de $/ \mathrm{y} /{ }^{1}$. Esta tesis se opone a la interpretación que yo había ofrecido hace ya veinte años ${ }^{2}$; para mí, el yeísmo rehilado era general entre los porteños por lo menos desde los inicios del siglo XIx, que era la fecha más antigua de la documentación que había logrado reunir. He leído con el interés y la atención que merecen los argumentos y testimonios que presenta la señora Fontanella de Weinberg, pero no he podido ver en ellos las pruebas de la existencia de un yeísmo simple o sin rehilamiento. Se me permitirá, por lo tanto, que escriba estas páginas en favor de mi antigua interpretación de este punto, que pertenece a un tema por el que tengo particular afición. Siento, además, cierta obligación de hacerlo. La señora Fontanella de Weinberg toma como punto de partida de su tesis unas observaciones de Ángel Rosenblat; el eminente estudioso había creído ver ejemplos de este yeísmo simple en dos cartas de Juan Manuel de Rosas (1793-

${ }^{1}$ Véase de esta autora: "El yeísmo bonaerense en los siglos XVIII y XIX", Revista Argentina de Lingüistica, 1 (1985), 84-91; El español bonaerense. Cuatro siglos de evolución lingüistica (1580-1980), Hachette, Buenos Aires, 1987, pp. 99-100; "Un nuevo aporte sobre el rehilamiento bonaerense", $A L M, 27$ (1989), 269-274. En adelante citaré estos trabajos por las tres primeras palabras de sus títulos.

${ }^{2}$ Me refiero a mis "Notas para la historia del yeísmo", en Eugenio Coseriu y Wolf-Dieter Stempel (eds.), Sprache und Geschichte. Festschrifi für Harri Meier zum 65. Geburtstag, Wilhelm Fink Verlag, München, 1971, § 3, pp. 190198. En lo sucesivo remitiré a este estudio como "Notas". 
1875) ${ }^{3}$. Cuando escribí mi citado estudio no quise demostrar ] infundado de esta suposición, pues no deseaba molestar al Néstc de la filología hispanoamericana; me pareció que los testimonic de yeísmo rehilado que yo publicaba bastaban para hacer ver qu dominaba en forma total en Buenos Aires ${ }^{4}$. No ha ocurrido a y dado, además, que el llorado Rosenblat ya no se encuentra eı tre nosotros, me he decidido a tomar posición ante el supues1 yeísmo no rehilado de Rosas; lo hago persuadido, por otra part de que la discusión de este punto en nada perjudica la posició de primera fila que unánimemente se le reconoce a Ángel Roseı blat entre los estudiosos del español de América. En cuanto a señora Fontanella de Weinberg, me complazco en declarar aq que su obra me inspira no ya respeto, sino admiración.

De lo que acabo de exponer se desprende que mi trabajo ter drá dos partes: en la primera examinaré los argumentos de $\mathrm{R}_{1}$ senblat y en la segunda los desarrollos que les dio la señora For tanella de Weinberg.

\section{El uso De $I$ POR Y EN Rosas}

No debe olvidarse que el trabajo al que pertenecen las observ. ciones de Rosenblat sobre el yeísmo porteño apareció una docer de años después de que hubiera abandonado la Argentina pa establecerse en Venezuela. Se tiene la impresión de que en algı nos casos ha de haberle faltado en Caracas la bibliografía apr piada para continuar una investigación interrumpida en el $\mathrm{m}$. mento de su partida. Así, por ejemplo, nos dice que "no hemı encontrado ningún caso [se. de yeísmo] en los documentos c Rosas"5. Evidentemente, Rosenblat no llegó a tener ocasión c manejar un cierto número de papeles de Rosas, porque, de $h$

3 Ángel Rosenblat, Las generaciones argentinas del siglo xix ante el probler de la lengua, Universidad de Buenos Aires, Buenos Aires, 1961, p. 13, n. Este trabajo se había publicado previamente en la Revista de la Universidad Buenos Aires, 5 (1960), 539-584. Lo citaré como Las generaciones argentinas.

"Sólo me resultó imposible dejar de señalar en mis "Notas", p. 19 n. 40, que en Rosas se encuentra ampliamente documentado el yeísmo, ce tra la tesis de Rosenblat de que en el campo de Buenos Aires, de cuya hat sería representante Rosas, se mantenía la distinción $l l-y$. Aludí también a inaceptable de tomar a Rosas como hombre de la campaña porteña. Esta id y la no menos infundada de establecer una oposición entre el habla de la ci dad y la del campo, parecen ecos lejanos del Facundo.

${ }^{5}$ Las generaciones argentinas, p. 13, n. 8. 
berlo hecho, habría hallado sin dificultad ejemplos de yeísmo ${ }^{6}$. Hay que tener presente esta circunstancia al considerar su tesis de que Rosas tenía un yeísmo sin rehilamiento. Se basa en pasajes de tres cartas de Rosas publicados en la Historia de la Nación Argentina que dirigió Ricardo Levene ${ }^{7}$. En ellos encontró las formas "suias, cuio, vaia, etc." y sacó entonces aquella fatídica conclusión de que: "Si la $y$ consonántica la podía reproducir con $i$ es evidente que no la pronunciaba rehilada" 8 . Así nació la idea de que Rosas reproducía su pronunciación al escribir.

Supongamos el siguiente ejemplo para mostrar lo insostenible de esta tesis. Si un filólogo de fines del siglo Xxi examinara papeles de Rosenblat podría concluir muy fácilmente que el inolvidable estudioso había extendido la pronunciación rehilada de $y$ a la posición postvocálica de un núcleo silábico e inclusive a la conjunción $y$. Para esto le bastaría señalar sus grafías hay, soy, rey, $y$, y razonar: "Si reproducía con $y$ el sonido palatal de estas palabras, éste debía ser rehilado; de lo contrario habría escrito hai, soi, rei, i"'. Por lo tanto, con esta lógnica habría que concluir que Rosenblat pronunciaba hay libros [áž líbros], soy feliz [sóž felís], Rey de España [rèžž despána], clásicos y modernos [klásı̣kos ž modérnos].

Este estupendo descubrimiento a que llegaría nuestro filólogo del siglo XxI descansaría en dos errores: 1) tomar a la ortografía corriente por una ortografía fonética y considerar que quienes escriben están reproduciendo con ella los sonidos de su habla. No hay tal; la ortografía en uso es un sistema autónomo, con sus reglas e historia propias. Las letras pueden coincidir con determinados sonidos, pero no es necesario que ocurra esto; si así fuera, no habría habido que inventar el alfabeto fonético. 2) También habría que censurar por su método al filólogo del futuro. La absurda conclusión en que desembocó se debe a haber ignorado la situación de $i$ e $y$ en la ortografía española de los años en que vivió Rosenblat. Las grafías hay, soy, rey, y, no reflejan la pronunciación de Rosenblat sino las reglas de ortografía de la Real Academia Española, seguidas por él, por todos los porteños, por todos los argentinos y por todos los americanos y españoles de su tiempo. La Academia había repartido los usos de $i$ e $y$, asignando la primera a la vocal y la segunda a la consonante, con la excep-

${ }^{6}$ Véase n. 4.

${ }^{7}$ Imprenta de la Universidad, Buenos Aires, 1950, t. 5, $2^{\mathrm{a}}$ sec., pp. 23, 24 y 632.

${ }^{8}$ Las generaciones argentinas, p. 13, n. 8. 
ción de que la $y$ podía representar el sonido semivocálico en algi nos diptongos decrecientes y en la conjunción copulativa. Es quiere decir que aunque Rosenblat escribiera hay con la misn $y$ que usaba en mayo [mážo], podía, sin embargo, pronunciar $h_{\text {, }}$ [ái]. En consecuencia, al filólogo del siglo Xxi habría que rec mendarle que antes de sacar conclusiones sobre la pronunciacić de un autor, tuviera en cuenta la ortografía de su época.

$\mathrm{Si}$ aplicamos estas reflexiones al caso de las grafías de $i \mathrm{p}$ $y$ de Rosas, nos damos cuenta de que no se las puede comprend sin establecer claramente los valores y usos de estas letras por 1 años en que escribía; y aun hay un paso previo a éste: bosquej. sobre la base de alguna documentación la manera cómo las $\mathrm{m}$ neja don Juan Manuel. A este propósito, la manera cómo se e: presa Rosenblat puede inducir a error al lector. Nos dice que 1 encontrado en cartas de Rosas las formas "suio, cuio, vaia, etc." pero el "etc." con que se cierra esta enumeración no signifi que existan también formas como, por ejemplo, *hoio, *aiuda *bueies. Los pasajes de las cartas de Rosas examinados por $\mathrm{R}$ senblat presentan seis casos de $i$ por $y$; él cita a suio, cuio, val y las otras tres formas resumidas en el "etc." son suia, cuios, decir unas meras variantes de género y número del posesivo . tercera persona y del relativo cuyo, y además cuio, que apare una segunda vez. Así, lo que está en juego para la grafía cor son solamente tres palabras: suio, cuio, con sus variaciones mc fológicas, y vaia; la consonante palatal intervocálica de otras $\mathrm{p}$ labras siempre la escribe Rosas con $y$. La conjunción $y$ consta temente se encuentra escrita con $y$ griega, lo mismo que pronombre yo; también se halla arrayo (dos veces) y el trío ayudac ayuda, ayudándome. En conclusión, la $i$ no alterna anárquicamer con la y, como una manera posible de representar su sonido, si] es una grafía reservada para ciertas palabras.

Ahora bien, un examen en mayor escala de cartas de Ros ofrece el mismo cuadro, con apenas una ligera mayor comple dad $^{9}$. He revisado cuatro cartas suyas a Juan Ramón Balearc

${ }^{9}$ Para no recargar con excesivas notas mi presentación, de manera . cepcional en este apartado señalaré el número de página de una obra a cor nuación del ejemplo que de ella doy en el texto. Las cartas de Rosas y de c táneos suyos que manejo se encuentran en los siguientes libros: ERNESTO Celesia, Rosas. Aportes para su historia, Ediciones Peuser, Buenos Aires, 19. en mi texto, la sola indicación de un número de página remite a este lib Si al número está antepuesto un "II", la referencia corresponde al segur volumen de esta obra, publicado con el mismo título (Editorial y Libre 
dos a Felipe Arana, doce a Vicente González y un decreto sobre la emisión de billetes, en total diecinueve documentos del año 1833. En ellos está escrito invariablemente suia (468, 475, 478), cuio, cuia, cuios, cuias $(378,433,451,455,463,467$ [bis], 478 [bis], 481), vaia $(382,403,415,461,463,473)$ y vaian $(451,474)$. Aparecen las formas verbales creise (sic por creiese; 379), creiesen (462), ereiendo (467) y concluio (382). También escribe Cuien (413), el apellido que en la página siguiente es ortografiado correctamente Cullen (414); algún tiempo atrás había escrito Cuyen (455). Es de notarse que tres veces escribe maior (414 [bis], 454) y una mayor (415), una vez haia (414) frente a una abrumadora mayoría de haya $(413,415,416,455,461,462$, etc.) y que existe un vaya (433) en oposición a los arriba señalados vaia.

Así, pues, el uso de $i, y$ en estas cartas coincide en lo fundamental con el que presentan los pasajes leídos por Rosenblat: suio, cuio, vaia, se escriben con $i$ en forma casi total; a ellos hay que agregar ahora algunas desinencias verbales: creiesen, etc., concluio y otros casos en que alternan y con $i$ : mayor / maior, Cullen / Cuien / Cuyen, haya / haia y vaya / vaia. Se confirma, por lo tanto, que Rosas no emplea $i$ e $y$ al azar, sino que está siguiendo una regla de escribir ciertas palabras con $i$; existen, además, unos casos de doble escritura que pueden deberse a que no tenía tan firme la regla en unas palabras como en otras. Parece tratarse de algo semejante a los descuidos que a veces comete a propósito de conocidas reglas ortográficas. Por ejemplo, aunque en sus escritos se encuentra generalmente la grafía Yndios, siguiendo la costumbre de escribir $Y$ ia $i$ mayúscula, a veces se distrae y hallamos Indios (414, 468, 476 [ter], 478). También es lo habitual en él escribir Buenos Ayres, paysano, según la regla de que la $i$ en un diptongo decreciente se cambia por $y$, pero alguna vez se le escapan Buenos Aires (451) y paisano (455).

Para terminar estas observaciones sobre la ortografía de Rosas, debo indicar que en documentos suyos posteriores a 1833 hay un cambio en el uso de $i$ e $y$ que acabo de esbozar. Todavía encontramos tuio en un texto fechable entre 1820 y 1835 (II, 533) y en otro de 1835 (II, 400), pero en las cartas del exilio Rosas

Goncourt, Buenos Aires, 1968). Otras dos publicaciones de cartas de Rosas se citarán de esta manera: Gómez = JOSÉ RAED, Rosas. Cartas confidenciales a su embajadora Josefa Gómez. 1853-1875, Humus Editorial, Buenos Aires, 1972. Roxas = José RAED, Cartas inéditas de Rosas-Roxas y Patrón, I. 1852-1862. Monarquía republicana, Platero, Buenos Aires, 1980. 
escribe tuyo en 1853 (II, 517), 1859 (II, 377), 1861 (II, 380), 186 (II, 525), y tuyas en 1861 (II, 379, 524), lo mismo que suya e: 1853 (II, 514, 516) y 1866 (Gómez, 82), y suyo en 1858 (Roxas, 99 y 1871 (Gómez, 164). También, aunque se lee un par de veces vai en 1838 (II, 438, 439), ya en 1839 aparece un vayan (II, 444) asimismo el año anterior don Juan Manuel había escrito cuya (I] 439); digamos, con todo, que en 1862 vuelve a leerse la form vaia (Roxas, 206). Sin embargo, durante sus años de Southamf ton mantuvo la $i$ de las desinencias verbales; a más del poco má arriba citado vaia, lo acreditan leiendo, 1862 (Roxas, 201) y 186 (Gómez, 117) ineluie, 1865 (Gómez, 65), y ereiendo, 1866 (Gómé 76). Pero estos textos tardíos no muestran en realidad un abar dono del criterio de usar $i$ con función consonántica, sino sól una reducción del material léxico al cual se aplica: se excluye tuyo, suyo, cuyo, y queda reducido a las desinencias verbales.

¿Era privativo de Rosas el uso de $i$ e $y$ especializadas léxić mente? Para acercarme a la cuestión he repasado cartas que e 1833 le dirigieron corresponsales suyos: trece de Juan Ramó Balcarce (1773-1836), once de Felipe Arana (1789-1857), cuatr de Manuel V. Maza (1779-1839), ocho de Vicente González (ú timo cuarto del siglo XviI-1861) y seis de Prudencio Rosá (1800-1857); también he leído una carta que ese mismo año $e_{:}$ cribió Manuel A. Pueyrredón (1802-1865) a Vicente Gonzále: En Balcarce se encuentra cuyo (383, 386, 387), cuyas (386), may (381, 383); en Arana cuyo (423), cuya (423), cuyas (403, 428), suy (409, 420), mayor (399 [bis], 400 [bis], 421, 429), restituya (398 incluyo (400), concluyo (423, 427, 430), etc.; en Maza tuyo (441 443 [bis], 445), tuyas (442), suyos (442), mayor (449), mayores (444 creyéndonos (439), creyerases (sic, 440), destruyo (438), etc.; en Gor zález cuya (460), mayor (460), baya 'vaya' (452), trayendo (469), cr yendo (469); en Prudencio Rosas tuyo (485, 486, 489 [ter]), tuy (492), mayor (485), mayoría (485), rayar (491); en Pueyrredón suy (500, 503), cuya (503), mayor (499, 500, 502), mayoría (503), ayud ban (499), creyó (502), apoyan (502). Estos personajes, como se v escriben uniformemente $y$ para la consonante intervocálica. 1 deja de haber, sin embargo, um par de casos en que se empl la $i$; un cuia $(437,449)$ de Maza y un concluio (489) dc Prudenc Rosas coinciden exactamente con ejemplos del uso de $i$ en dc Juan Manuel. Lo que, en mayor o menor grado, se encuent en todos estos autores es la incertidumbre en el uso de $i, y$ pa los diptongos decrecientes y en el de $Y$ para la $i$ mayúscula. A: por ejemplo, Balcarce escribe estoi (381 [bis], 383, 384 [bis]), p 
ro hay (380, 381, 382 [bis], 386), Reynafé (383) y Reinafé (384), Yndios (380) e Indios (381 bis).

Las citas anteriores, empero, sólo muestran que entre la gente que trataba Rosas no era corriente la repartición léxica de $i$ e $y$ que él practicaba. Esto no quiere decir que fuera una invención suya. La podemos encontrar en las Memorias curiosas o "Diario" de Juan Manuel Beruti (1777-1856), comenzado a redactar por este autor en $1790^{10}$. Beruti ofrece una singular coincidencia con Rosas en la ortografía de $i$ e $y$. Escribe constantemente suio, suia, suios, suias (por la naturaleza del texto no hay ejemplos del posesivo de segunda persona) y cuio, cuia, cuios, cuias, y asimismo aparece $i$ en alguna palabra como maior y derivados (VI, 340, 344 [bis], 345; VII, 142, 149, 155; etc.), escrita de la misma manera por Rosas, y en desinencias de algunos verbos: instituió (VI, 345), concluió (VII, 403, 405; X, 453; XI, 169, 475; XII, 152; XIII, 193, 201). La coincidencia de Beruti con Rosas se extiende a que en cierto momento el diarista también abandona o disminuye las grafías con $i$ y las reemplaza por otras con $y$. Así, desde el 23 de diciembre de 1812 cuyo, con sus variantes morfológicas, empieza a alternar abrumadoramente con cuio (cf. XII, 320, 327, 329, 337 [bis], 351, etc.) y pronto lo elimina totalmente. Algo más tar$\mathrm{de}$, suio (y variantes) sufre la competencia de suyo, pero resiste con éxito; hallo suia en XII, 344 [bis], 350, y suio (403), pero suyos (468); en XIII: suia (173), suios (184), pero suyos (172), suio (281). Frente al abundante maior ahora también aparecen mayor (XII, 116, 120, 122, 158 [bis], 162, 168, etc., hasta el fin de las Memorias), y mayores (XII, 362, 445, 448, 473, 480; XIII, 175-179). A partir de la entrada del 22 de septiembre de 1811 comienzan a encontrarse grafías como concluyeron (XII, 115, 147), concluyendo (XII, 140, 181, 226, 228), concluyó (XII, 177, 181), que continúan hasta que se acaba la obra, sin que por ello desaparezca la ya vista forma concluió.

Saquemos las conclusiones de lo que hemos visto. Si bien en los coetáneos de Rosas parece seguirse la norma de escribir $y$ la /y/ intervocálica, no deja de haber vacilaciones en este uso; mayores son las oscilaciones al emplear $i, y$ para los diptongos decre-

${ }^{10}$ Se publicó en la Revista de la Biblioteca Nacional (Buenos Aires), tomos VI-XIII (1942-1945). Lo citaré en el texto dando los números del tomo (en romanos) y de la página (en arábigos). El "Diario" de Beruti se volvió a publicar, modernizando la ortografía, en la Biblioteca de Mayo, Buenos Aires, 1960 , t. 4 , pp. 3647-4150. 
cientes y para la mayúscula de la $i$. A más de presentar es cuadro, en Rosas y Beruti encontramos además convenciones e peciales sobre el uso de $i, y$ e inclusive variaciones en estos subsi temas dentro de los mismos individuos a lo largo del tiempo. $T$ do esto indica con claridad meridiana algo obvio: por aquell años no estaba normalizado el empleo de estas letras. Esta situ ción se daba en todo el dominio de la lengua española y venía c siglos atrás. El problema que planteaban $i$ e $y$ era su uso anárqu co: $i$ era la letra de la vocal, pero se empleaba también para consonante, continuando un uso que tenía sus raíces en la épor de orígenes del idioma ${ }^{11}$; la $y$ no sólo servía para la consonant sino además tenía extenso uso para representar la vocal, c acuerdo con su valor en el alfabeto griego. Al inaugurar sus aci vidades, la Real Academia Española se propuso terminar con e ta anarquía especializando a cada una de las letras: la $i$ habr de servir para la vocal y la $y$ para la consonante ${ }^{12}$; con todo, d bió hacer muchas concesiones al uso de $y$ como vocal, que só fueron reducidas a sus límites actuales en sus ediciones de la $\mathrm{Gr}$ mática de 1815 y $1880^{13}$. No parece, tampoco, que por un lar tiempo haya podido desterrar el uso de la $i$ para la consonante ${ }^{1}$

Las grafías suio, cuio, vaia, que Rosenblat encontró en Rosa no son más que un intento de resolver esta anarquía ortográfic Simplemente, se adopta la convención de escribir la consonan con $y$, salvo en unas cuantas palabras que se reservan ( ${ }_{\mathfrak{c}} \mathrm{O}$ en qI se mantiene?) para la $i$. Es un procedimiento análogo e inver al que utilizó la Academia para la vocal palatal alta: su letra $i$, menos en algunas voces en que se usa $y$. Siendo así las cosa Rosas no ha empleado la $i$ porque su sonido se parecería al , una supuesta [y] suya, sino porque era una de las grafías trac

${ }^{11}$ Cf. Ramón Menéndez Pidal, Orígenes del español, $3^{\text {a }}$ ed., Espa: Calpe, Madrid, 1950, $\S 7_{2.3}$; Cantar de Mio Cid, $3^{\text {a }}$ ed., Espasa-Calpe, M drid, 1954, t. $2, \S 51_{4}$.

12 "Discurso proemial de la orthographia de la Lengua Castellana Diccionario de Autoridades, Madrid, 1726, t. 1, p. lxxi.

${ }^{13}$ Véase la historia de la cuestión en Abraham Esteve Serrano, Estua de teoría ortográfica del español, Universidad, Murcia, 1982, pp. 129-134.

${ }^{14}$ Manuel Hidalgo Caballero, "Pervivencia actual de la $l l$ en el su. este de España", RFE, 59 (1977), p. 134, cita la doble grafía contribuien tribullen de una Relación sevillana de 1786. Para el uso indistinto de $i, y$ inter cálicas en Puerto Rico durante el siglo XVIII, véase MANUEL ÁlvaR Nazario, Historia de la lengua española en Puerto Rico, Academia Puertorriq1 ña de la Lengua Española, San Juan, 1991, p. 508. Creo que investigacior en otros países mostrarían que la situación era general en el mundo hispánir 
cionales de la /y/. En cuanto la grafía que es, a la $i$ hay que ponerla en relación con la ortografía, no con la fonética. Con la $i$ (como con la y) se podía escribir tanto una $y$ simple como una $y$ rehilada, porque en función consonántica sólo significaba “consonante palatal central no africada". Esto es tan cierto que creo es posible probar documentalmente que la consonante que algunos porteños escribían $i$ sonaba efectivamente [ž]. Lo perfecto hubiera sido poder aducir aquí el testimonio del propio Rosas. La fortuna no me ha ayudado en este punto y no lo he encontrado; he hallado la prueba, en cambio, en Beruti y considero que, aunque menos espectacular que la evocación de la [ž] del mismo don Juan Manuel, para el caso sirve igualmente, pues ambos tenían inclusive un idéntico sistema de especialización léxica de $i$ e $y$.

Al final del año 1851 hace Beruti un balance de lo ocurrido en este lapso y apunta que "el Gobernador del Entrellidos d" Justo Vrquiza" (XIII, 269; cursivas mías) había aceptado la renuncia anual al poder elevada por Rosas. El Entrellidos es "el Entrerríos", la manera antigua de llamar lo que hoy se conoce como la "provincia de Entre Ríos". Se trata de una de las frecuentes ultracorrecciones de Beruti o, más precisamente, de una doble ultracorrección. Primero hay la falsa reposición de una $d$; nuestro autor ha tomado a -ios como un caso de pérdida de $d$ en la terminación -ido (cf. tronio < tronido) y lo ha corregido en -idos, tal como había escrito sarado 'sarao' (XI, 161), Estanislado 'Estanislao' (XII, 188, 356, 459), el puerto del Callado 'Callao' (XII, 367). Y la extraña ultracorrección de $l l$ por $r r$ ¿cómo se explica? Se comprende fácilmente teniendo en cuenta dos puntos. En primer lugar, que Beruti, como todos los porteños, era yeísta, según lo manifiesta abundantemente su "Diario", sobre todo en forma de ultracorrecciones: paveyón 'pabellón' (VII, 351), balloneta 'bayoneta' (VIII, 181), hallan 'hayan' (X, 454), plalla 'playa' (XI, 153), callese 'cayese' (XI, 480), Golleneche 'Goyeneche' (XII, 121), oyas 'ollas' (XII, 348), etc. Beruti, pues, reemplazaba la palatal lateral por esa palatal central que escribía con $i, y$. A esto hay que añadir que en Entre Ríos la $r r$ se pronuncia asibilada, como en toda una mitad de la República Argentina ${ }^{15}$. La pronunciación

15 Véase Berta Elena Vidal de Battini, "Extensión de la $r$ múltiple en la Argentina", Fil, 3 (1951), pp.181-185; El español de la Argentina, Consejo Nacional de Educación, Buenos Aires, 1964, pp. 112-113; NÉLIDA E. DoNNI DE Mirande, “Aspectos del español en el litoral argentino", Rom, 5 (1972), pp. $125-126$. 
de la $r$ asibilada suena [ž], por lo cual ocurre que este sonido e identificado por los entrerrianos como $r r$ y por los porteños com -y; así, al escuchar [žúbja] los primeros piensan en rubia y los c Buenos Aires en lluvia ${ }^{16}$. Se ve, pues, lo que ha de haber pasi do. Beruti escuchó Entrerríos en boca de algún entrerriano, o s€ que oyó [eñtrežíos] y, de acuerdo con su peculiaridad dialecta interpretó Entreyios; luego, la conciencia de la inferioridad d yeísmo lo llevó a reponer una $l l$ inexistente. Ahora bien, obsérvı se que si su $/ y /$ no hubiera tenido rehilamiento, nunca la habr: podido confundir con una $r r$ asibilada.

\section{CAMbIO FONÉTICO Y PERMANENCIA DE NORMAS}

Otro punto de la exposición de Rosenblat merece comentari Ya hemos visto (cf. n. 4) que el llorado filólogo pensaba que R sas, al revés de su mujer Encarnación Ezcurra, no practicaba yeísmo y explicaba esta supuesta diferencia como una oposicić entre el habla conservadora de la campaña y la innovadora de capital. Esto lo llevó a postular la más amplia tesis de que en 1 i regiones yeístas la confusión ll-y todavía no era general pr aquellos años; para ello se apoyó en unos textos de Sarmient escritos durante la polémica que desató en 1843 su Memoria sol ortografía americana, y de su examen concluía que "es evidente qu el yeísmo no estaba todavía impuesto"17. Rosenblat se basal principalmente en la siguiente frase de Sarmiento: "Yo pregun

16 Véase el interesante trabajo de Adriana C. Gandolfo, "Spanish $l l$ and $r r$ in Buenos Aires and Corrientes", Proceedings of the Ninth Internation Congress of Linguists, Mouton, The Hague, 1964, pp. 212-215. Estimo que que aquí se dice de la $r r$ asibilada de Corrientes vale asimismo para la de En1 Ríos. Inés T. Abadía de Quant, "Procesos de cambio en el área palatal los nativos de la capital de Corrientes, Argentina", ALHis, 5 (1988), p. n. 1, cuestiona la existencia de la pronunciación [ž] de $r r$, aducida por la pr Gandolfo. Yo no me siento calificado para intervenir en esta discusión. \$ embargo, creo que aunque las $r$ asibiladas de correntinos y entrerrianos $\mathrm{ft}$ ran sólo [ [̌] y no [̌̃], se cumpliría asimismo la identificación con la y rehila porteña, pues en este punto se trata sólo de equivalencias entre subsisten: dialectales, no de identidades fonéticas. Así, por ejemplo, es tradicional ide tificar la $y$ rehilada porteña con la [ž] francesa o inglesa, por más que el soni argentino tenga una articulación más adelantada y menos rehilamiento q el de las lenguas con que se lo compara.

17 Las generaciones argentinas, p. 13, n. 8. 
a los redactores del Mercurio si dicen ellos yebar por llevar, quero por quiero, sordao por soldado" 18 . Ciertamente, los redactores del distinguido periódico dirían llevar y no yebar, pero esto no autoriza a pensar que en Valparaíso convivían personas yeístas junto con otras que, como la gente del Mercurio, mantenían la $l l$. Obsérvese que Sarmiento atribuye a los periodistas no sólo la pronunciación de $l l$, sino también la de la $v$, y esto nos alerta inmediatamente sobre el carácter no espontáneo de su habla. Así, no parece tratarse de que el yeísmo "todavía no estuviera impuesto", sino de que los periodistas del Mercurio reintroducían la $l l$ por un afán de corrección, tal como hacían al reemplazar la $b$ por la $v$. Las palabras de Sarmiento, por lo tanto, no se refieren a la extensión del cambio fonético, sino a su aceptación social; no prueban que el yeísmo no fuera general, sino sólo indican que no formaba parte de la norma culta de pronunciación. Sobre este punto contamos con el inapreciable testimonio de Bello; en sus "Advertencias sobre el uso de la lengua castellana" decía en 1834:

Los que se cuidan de evitar todo resabio de vulgarismo en su pronunciación procuran no equivocar la $r$ con la $l$, diciendo, verbigracia, cárculo por cálculo; la $g$ con la aspiración de la $h$, pronunciando güevo en lugar de huevo; ni la $y$ con la $l l$, confundiendo haya, tiempo de haber, con halla, tiempo de hallar; y si se aspira a una pronunciación más esmerada, distinguirán también la $s$ de la $z$ o la $c$, la $b$ de la $v$ y la $y$ consonante de la $i$ que forma diptongo con la vocal que se le sigue ${ }^{19}$.

"Los que se cuidan de evitar todo resabio de vulgarismo" no pronuncian $y$ por $l l$, es decir, no se trata de que el yeísmo no estuviera impuesto, sino de que era considerado un vicio de dicción; por eso lo evitaban los redactores del Mercurio al mismo tiempo que, "aspirando a una pronunciación más esmerada", distinguían también $b$ y $v$. Al año siguiente Bello escribirá en sus Principios de la ortología y métrica de la lengua castellana:

${ }^{18}$ Domingo F. SARmiento, Obras, Imprenta Gutenberg, Santiago de Chile, 1886 , t. 4 , p. 90.

19 Andrés Bello, Obras completas, Ministerio de Educación, Caracas, 1951, t. 5, p. 161. 
$L l, Y$. Es un vicio confundir estos dos sonidos, como lo suelen $\mathrm{h}$ cer los americanos y andaluces ${ }^{20}$.

Obsérvese que dice que "los americanos", así a secas, suel practicar el yeísmo. No se refiere a "algunos americanos" o "muchos americanos". Evidentemente, los americanos que c noció Bello (incluidos los chilenos entre los cuales vivía) er: yeístas, en tanto no se cuidaban "de evitar todo resabio de vulg rismo en su pronunciación".

Lo que Sarmiento dice coincide con el cuadro de Bello. El a gentino eliminó de su alfabeto a $z$ y $v$ porque los sonidos de est letras no existían en América. Al ser acusado de legitimar los v cios de pronunciación, negó ofendido la imputación y reiteró criterio de su Memoria: cuando una pronunciación pertenece só a la plebe de la sociedad, se la puede considerar un vicio; si es extendida por toda la sociedad, ya no es un vicio sino una tran formación de sonidos, y constituye una forma legítima de $\mathrm{h}$ blar $^{21}$. Fundándose en este criterio, explica por qué su ortogr fía no puede sancionar el yeísmo, eliminando la $l l$ :

$Y$ ya que se me viene usted con lo de la $l l$ y la $y$, la $g$ y la $j$, cuy diferencias se deben hacer notar a los alumnos, le diré que esos d fectos de pronunciación adquiridos en el seno de la familia, se pu den y se logran corregir en efecto, precisamente porque no son $g$ nerales; porque la sociedad ejerce una influencia niveladora sob todos los individuos, porque no hay muchos que los cometan, o no toc los cometen; de manera que hay un tipo vivo a que arreglarse, y ar él van desapareciendo poco a poco los defectos ${ }^{22}$.

El yeísmo no es un hecho general, nos dice Sarmiento, pe la cuantificación que de él hace no queda clara: ¿es un vicio q1 no muchos cometen o uno en que no todos caen? Un artículo post rior nos sacará de la duda. Tres meses más tarde comentó alb rozado una reforma ortográfica propuesta en México, que ten el mismo sentido americanista que la suya y eliminaba las letr de los sonidos que no existían en el Nuevo Mundo; iba, sin er bargo, más lejos que su Memoria, porque desterraba no sólo a

${ }^{20}$ Obras completas, Ministerio de Educación, Caracas, 1955, t. 6, p. 27

21 Obras, t. 4, p. 90.

22 Ibid., p. 105 (cursivas mías). 
$z$ y la $v$, sino también a la $l l$. Con esto Sarmiento ya no está de acuerdo:

Por otra parte, y éste es el defecto capital de la reforma propuesta en Méjico, la $l l$ tiene valor real en la pronunciación, no sólo en la América toda, sino en Méjico mismo, según confesión del mismo escritor. No hay, pues, hecho constante. La extinción no está consumada aún, $y$ la ortografía no debe anticiparse a ultimar un sonido, aunque dé señales de agonía. No sucede otro tanto con la $z$. Desde Méjico acá se ha perdido. No existe tipo vivo de él, si no se llama a un español que nos lo haga oír ${ }^{23}$.

Aquí puede verse bien el pensamiento de Sarmiento sobre el yeísmo. Afirma que la $l l$ "tiene valor real en la pronunciación", pero hay que entender lo que quiere decir con esto. "Valor real en la pronunciación" todavía lo tenía la $l l$ en Buenos Aires cuando yo iba a la escuela, donde los maestros nos la hacían pronunciar en las clases de lectura. Cualquier persona que pasara frente a las aulas podía oír una $l l$ porteña; también podía oírla si iba al teatro, encendía la radio o asistía a un acto oficial en que se pronunciara un discurso. Se habría equivocado de medio a medio quien hubiera deducido de estas experiencias que el yeísmo no estaba todavía impuesto en Buenos Aires: el yeísmo rehilado era general en toda la población, desde la más encopetada sociedad hasta el más humilde atorrante; la $l l$ sólo conservaba el prestigio de pronunciación culta y como tal se empleaba en manifestaciones artísticas o solemnes, y se enseñaba a la infancia para que en su momento pudiera también realizarlas ${ }^{24}$. Este Buenos Aires de los años treinta representaba la última fase (probablemente ya debilitada) de una situación que ha de venir de siglos atrás, aunque por el momento sólo podemos precisarla un poco para la centuria pasada. Se trata de una repartición de funciones: el yeísmo pertenece al habla cotidiana y la distinción $l l-y$ al habla culta.

${ }^{23}$ Ibid, p. 180 (Todas las cursivas son mías excepto tipo vivo).

24 Todavía en 1938 la Academia Argentina de Letras instaba a que se usara la $l l$ en la pronunciación culta; cf. su respuesta a la consulta de la Dirección de Correos y Telégrafos sobre la pronunciación que debía usarse en la radio, en el $B A A L, 6$ (1938), p. 442. Inclusive cuando en 1964 un académico argentino propuso quitar la tacha de incorrección al yeísmo, lo hizo dejando constancia de "la superioridad expresiva que la pronunciación de la $l l$ implica"; cf. IV Congreso de Academias de la lengua española. Actas y labores, Academia Argentina de Letras, Buenos Aires, 1966, p. 153. 
Éste es el cuadro que atestigua Sarmiento para el Chile de s tiempo. No cabe dudar de que escuchaba pronunciar la $l l$, pes sería en boca de gentes como aquellos redactores del Mercurio c Valparaíso, que en su alarde de cultura llegaban a pronunciar v. El sonido de la ll tenía, sí, "valor real", pero en la modalidé culta del habla, entre "los que se cuidan de evitar todo resab de vulgarismo", como decía Bello. No pertenecía al habla c rriente, donde dominaba el yeísmo.

A un estudioso moderno, formado en la lingüística y en la $\mathrm{f}$ nética y él mismo miembro de una sociedad de masas, puede $r$ sultarle difícil de comprender que se considere real un sonido qi existe sólo en una variedad estilizada de hablar. Aquí convier recordar que la cultura pesaba más en la vida del siglo XIx qi en la del actual y no es de extrañar, por tanto, que se pensa: que los modos cultos de hablar eran tanto o más reales, en cuan manifestaciones de una determinada realidad histórico-culturc que las formas descuidadas y sin tensión espiritual de una co: versación espontánẹ. Esto no significa que las realidades cult no pudieran también desaparecer, y más para una persona con Sarmiento, que, en cuanto romántico, no dejaba de tener su fu go revolucionario. Afirma el "valor real" de la $l l$ y que por el no se la debe eliminar del alfabeto americano, pero toda su d fensa en este punto consiste en el nada alentador argumento , que "la extinción no está consumada aún", imagen fúnebre $r$ petida poco después al decir que la $l l$ "da señales de agonía". ? obvio que esta $l l$ moribunda que escuchaba Sarmiento debía t ner una vida muy reducida.

En resumen: Sarmiento testimonia la existencia de $l l$, pe también muestra que tenía una vida precaria y que estaba . trance de extinción. En consecuencia, hay que invertir la fra de Rosenblat de que para Sarmiento "el yeísmo no estaba tod vía impuesto" y sentar que para el sanjuanino "la ll todavía 1 había desaparecido del todo". Esta formulación se ajusta al h cho de que las observaciones de Sarmiento no corresponden tiempo de propagación del yeísmo, sino al posterior de la const vación de la antigua norma distinguidora en los estilos superior del habla.

2. Pasemos ahora a los trabajos de la señora de Weinberg. Sig la idea de Rosenblat de que en el siglo xix existió un yeísmo : rehilamiento, y la refuerza con nuevos argumentos. También 
acompaña en creer que el yeísmo todavía no estaba impuesto, reinterpretando esta posición en el sentido de que lo que no estaba impuesto aún era el yeísmo rehilado. Por otra parte, la señora de Weinberg me favorece aceptando mis noticias sobre la existencia del yeísmo rehilado en Buenos Aires, pero se aparta de mí al pensar que no era un fenómeno general. De este modo, en su tesis venimos a tener razón tanto Rosenblat, que sostenía que había un yeísmo simple, como yo, que probaba que existía uno rehilado. Claro que, en instancia superior, ambos resultamos equivocados, porque no habríamos visto que se trataba de un caso de variación lingüística, por medio del cual se cumplía el cambio del yeísmo simple al moderno yeísmo rehilado. No debe extrañarnos, explica la señora de Weinberg, que en el siglo XIX coexistieran estas dos formas de yeísmo, "ya que - tal como se ha señalado en las últimas décadas- el cambio lingüístico lejos de ser instantáneo demora décadas, y en algunos casos siglos, antes de su generalización total'"25.

Yo estoy de acuerdo en lo fundamental con estas palabras y, siendo así, me parece innecesario entrar a discutir puntos de erudición o formulaciones de escuela. Al fin, lo que aquí interesa no es una cuestión de lingüística general como el carácter del cambio fonético, sino determinar si son fidedignas las noticias de ese yeísmo simple que habría coexistido con el rehilado en el Buenos Aires del siglo xIx. En la sección precedente he mostrado el espejismo que sufrió Rosenblat al respecto. Ahora añadiré que los testimonios de yeísmo que reuní en mi estudio de 1971 o no dicen nada sobre la modalidad del yeísmo (y este silencio no deja de ser significativo) o cuando de alguna manera la revelan, indican la presencia de rehilamiento. No se puede documentar ninguna realización $[y]$ de la /y/ porteña.

\section{LO QUE DICEN LOS TESTIMONIOS DEL YEÍSMO PORTEÑO EN EL SIGLO XIX}

A principios del siglo pasado el yeísmo era general en Buenos Aires; así nos lo dice el gramático Antonio J. Valdés en 1817: la confusión de $l l$ e $y$ "ordinariamente se observa en la pronunciación y escritura"' ${ }^{26}$, y el naturalista francés Alcide d'Orbigny,

25 "Un nuevo aporte", p. 274.

26 Véase mis “Notas", p. 190. 
que estuvo en la ciudad en 1827,1828 y 1829 , comenta que “" vice uniforme [el yeísmo] semble niveler toutes les classes de société',27. Ninguno de estos autores dice o deja entrever que confusión se daba en dos modalidades distintas: ¿por qué vam a suponer que existía? En 1826 se critica en un periódico portei la "pronunciación viciosísima" de cierto actor que, en vez de d cir llanto, batalla, "pronuncia un ch medio líquido pero prolong do; y que dice chchchanto, batachchcha"'28 (más sobre este pasa en el apartado siguiente). Esto es, obviamente, una imitacic imperfecta de la $y$ rehilada. Si se supone que coexistían las fc mas $[\mathrm{y}]$ y [ž], hay que pensar que únicamente la casualidad 1 querido que en el teatro de Buenos Aires hubiera un actor qi pronunciara [₹z] por $l l$, y no [y] por $l l$. Pero esta línea de razon miento nos llevaría a la contradictio in adjecto de tener que postul una "casualidad constante" (es decir, una casualidad que de de ser casualidad), porque ocurre que todas las equivalencias $d$ sonido de la $y$ porteña con los de otras lenguas se deben siemp a hablantes con rehilamiento. Desde luego, no hay tal "ma suerte" de contar sólo con noticias de quienes tenían la realiz ción $[\check{z}]$ de /y/: es que no había otra. Esto es lo que muestra examen de los testimonios.

Un viajero inglés que estuvo en Buenos Aires en 1821 cuen que su yeísmo sonaba de esta manera: "Cavallo is pronounc Cavadjo, Calle Cadje, and yo jo"'29. Si hubiera habido otra m nera de pronunciar $l l$ e $y$ a más de la rehilada que se reproduc ésta era la oportunidad de decirlo. La $g$ e,i portuguesa en 18 : era transcripta por $y$ o, ultracorrectamente, por $l l^{30}$; de la corr $\epsilon$ pondencia de este sonido portugués con la $y$ porteña hay un tes monio de finales del siglo XviII ${ }^{31}$. Ahora, es difícil de creer $q 1$ los porteños transcribieran con su y la [ž del portugués si hubie habido entre ellos quienes la pronunciaran [y]; de haber sido és el caso, habrían empleado otra grafía para evitar errores en pronunciación del sonido. Probablemente se hubiera elegido c recuérdese alternancias como chajá yajá, que, por otra part son una prueba adicional de la pronunciación rehilada de lo q1

27 Ibid., p. 192.

${ }^{28} \mathrm{Ibid}$., p. 191.

${ }^{29}$ Loc. cit.

${ }^{30} \mathrm{Ibid}$, p. 193.

31 Cf. María Beatriz Fontanella de Weinberg, "El rehilamiento l naerense a fines del siglo XVIII", BICC, 28 (1973), pp. 341-342. 
se escribía con $y$ : no puede pretenderse que la $c h$ alternara con [y]. El ortografiar con $y$ la [ž] de otras lenguas es práctica habitual en Buenos Aires. Hilario Ascasubi (1807-1875) en una poesía de sus Trovos de Paulino Lucero (1853) se refiere en cierto momento a un tal "Mistre Yon'"32; este personaje no es otro que Mr. John Mandeville, ministro inglés en la Argentina durante el gobierno de Rosas. En cuanto al francés, Félix Frías (1816-1881) al informar en 1858 a Bartolomé Mitre de su conversación con el cónsul de Francia en Buenos Aires, el marqués de ForbinJanson, escribe repetidamente su nombre como "Forbin Yanson'"33. Es frecuente comparar la $y$ porteña con la [ž francesa; en el Río de la Plata la $l$, como la $y$ "a pris le son du $J$ français" cuenta Gaston Maspero (1846-1916), que estuvo en la región durante los años 1867 y $1868^{34}$. Paul Groussac (1848-1929) refiere en 1882 que en Tucumán " la $l l$ se pronuncia casi como la $g$ suave francesa; esta pronunciación es la de Buenos Aires, Santiago y Tucumán [...]'"35. No hay la menor restricción en estas aproximaciones; nada permite suponer que para $l l, y$ hubiera otro sonido a más del de " $J$ français"' o del de "casi como la $g$ suave francesa'.

En la mayor parte de estos datos y argumentos me basé en 1971 para sentar que el yeísmo rehilado ya debía ser general en Buenos Aires al principio del siglo xIx, y usaba el término "Buenos Aires"' en su sentido antiguo, que abarcaba tanto a la ciudad como a su campaña. Obsérvese que las noticias que he examinado no sólo no ofrecen pruebas de un yeísmo simple, sino inclusive excluyen esta posibilidad: no dejan la puerta abierta para interpretar que existiera otro tipo de pronunciación que no fuera el rehilado. No es de extrañar, pues, que la señora de Weinberg no haya podido ofrecer ninguna prueba directa de esa [y] que ha-

32 "Carta clamorosa del Mashorquero Salomón, a su aparcero Mariano Maza”, en Jorge Luis Borges y Adolfo Bioy Casares (eds.), Poesía gauchesca, F.C.E., México, 1955, t. 1, p. 138. Esta poesía fue escrita en 1846.

33 "Archivo de Félix Frías", Revista de la Biblioteca Nacional, Buenos Aires, 10 (1944), pp. 238, 239, 241, 466, 467, 468, 469 (bis), 470 (bis). Sólo la primera vez que lo menciona, Frías escribe "Forbin de Janson" (p. 237).

34 Véase mis "Notas", p. 190.

35 Citado por Ricardo L. J. Nardi, "Pablo Groussac y el español de la Argentina', Fil, 6 (1960), p. 116, y por ElenA M. ROJAs, Evolución histórica del español en Tucumán entre los siglos xvi y xix, Universidad Nacional de Tucumán, Tucumán, 1985 , p. 247 , n. 15. 
brían pronunciado algunos porteños; lo que hace es aducir datc que, tras una exégesis, revelarían indirectamente la existencia $c$ una $[y]$ en Buenos Aires. Se funda en tres testimonios; uno $c$ ellos es una reinterpretación de un dato aportado por Rosenbli y los otros dos proceden de investigaciones suyas. Es imposibl sin embargo, que toda la agudeza y conocimientos de la señoI de Weinberg puedan probar lo que estaría en contradicción co lo que sabemos por múltiples fuentes que era la pronunciació de la y porteña. Paso a ocuparme por separado de cada uno c los testimonios en que descansa su tesis.

La denuncia de rehilamiento de El Mensajero Argentino (182€

El Mensajero Argentino del 6 de junio de 1826 publica una crític de la pronunciación de los actores de teatro de Buenos Aires; ella me he referido en el apartado anterior, mencionando que $\mathrm{r}$ presentaba el sonido de /y/ como chchch. Ahora conviene copic el pasaje en su integridad; dice así:

El no dar a la $l l$ su pronunciación verdadera también es bastan frecuente en Buenos Aires; pero no tanto que sirva de excusa a $n$ die, y mucho menos a los señores del teatro. Alguno hay de ell que al pronunciar llanto, batalla y otras palabras con $l l$ parece $q t$ pronuncia un $c h$ medio líquido pero prolongado; y que dice $c h c$ chanto, batachchcha, etc. No hallamos otro modo de escribir esta pr nunciación viciosísima ${ }^{36}$.

En estas líneas se vuelve a testimoniar la extensión del yeísm en Buenos Aires; se lo llama 'bastante frecuente", pero esta e: presión no da toda la medida del fenómeno y en el mejor de lc casos sólo significa, como ya vimos, que la ll se mantenía en norma culta de hablar. Y aun no siempre. El autor de esta crític del Mensajero probablemente ha de ser el poeta neoclásico Jua Cruz Varela, según conjetura con buenas razones la señora c Weinberg ${ }^{37}$. Varela era la más alta figura cultural de su época

${ }^{36}$ Apud Á. Rosenblat, Las generaciones argentinas, p. 12, n. 7. Este pasa fue reproducido por la que señora de WEINBERG en "El rehilamiento bona rense", p. 339, y parcialmente en "El yeísmo bonaerense", p. 88, y " $\mathrm{C}$ nuevo aporte", p. 271.

37 “El rehilamiento bonaerense", pp. 339-340, n. 7. 
es comprensible que censurara la "pronunciación viciosísima" que se daba a ll-y en Buenos Aires; sin embargo, él mismo debía practicarla, porque en su solemne canto a la victoria de Ituzaingó hay una rima playa-halla ${ }^{38}$. Se ve, pues, que ni siquiera en la pronunciación culta vivía segura la $l l$.

Varela, o quien fuere el autor del artículo del Mensajero, reproduce el sonido del yeísmo como chchch, es decir, como una y rehilada. Ahora bien, la señora de Weinberg considera que esta declaración no sólo atestigua que había una y con rehilamiento, sino también prueba que junto a ella existía una $y$ sin rehilamiento. Su razonamiento es el siguiente: que se llamara la atención sobre las formas rehiladas "muestra que la realización [ž] aún no estaba generalizada, ya que cuando una pronunciación se generaliza en una determinada comunidad lingüística, sus hablantes pierden conciencia de la misma" 39 .

La autora se remite en este punto a una afirmación de Uriel Weinreich, William Labov y Marvin I. Herzog ${ }^{40}$, o sea convierte la denuncia de rehilamiento del Mensajero Argentino en un caso de variación lingüística, en que la variable rehilada de $y$ estaría ganando sectores de la población porteña frente a la variable más antigua sin rehilamiento. De las variables sólo se tiene conciencia en tanto son tales variables, es decir, cuando coexisten con otras variables, pues en cuanto se imponen como formas únicas pasan desapercibidas por no haber ya nada con que puedan contrastar. Basándose en esta idea la señora de Weinberg puede sentar que la noticia de que los porteños pronuncian chchch la $l l$ prueba al mismo tiempo que había un yeísmo rehilado (que es lo que dice) y que había otro no rehilado (que es lo que no dice). Toda esta construcción descansa en dar por bueno que había un "proceso de cambio" de [y] a [ž] en el momento en que se escribía la crítica teatral del Mensajero Argentino, y para suponer esto no hay más fundamento que creer que Rosas "conservaba" todavía la $y$ sin rehilamiento. En los apartados siguientes estudiaré los testimonios que a este respecto la señora de Weinberg añadió a los de

38 Véase mis "Notas", p. 193. Esta rima $l l-y$ desapareció en la versión corregida del poema, que es la que se imprime en las ediciones modernas de las poesías de Varela.

39 "Un nuevo aporte", p. 273; véase también "El yeísmo bonaerense", p. 90

40 "Empirical Foundations for a Theory of Language Change", en W. P. Lehmann y Yakov Malkiel (eds.), Directions for Historical Linguistics, University of Texas Press, Austin-London, 1968, p. 187. 
Rosenblat; aquí corresponde hacer un reparo de orden lingüístic a su argumento de que [ž] no debía ser general en 1826, pur de lo contrario el crítico del Mensajero no habría notado el sonic rehilado.

Que una pronunciación general pasa desapercibida es ur afirmación verdadera, pero que no puede entenderse sin matizi ciones, y sin duda Uriel Weinreich et al. la emitieron teniendo $\epsilon$ cuenta sus límites. Porque asimismo es un hecho que los hablaı tes pueden observar su lenguaje; en realidad, más que de una o] ción se trata de una actividad inherente al funcionamiento de lengua: es la función "metalingüística", según la bautizó R، man Jakobson. Se comienza a ejercitar desde la infancia en k momentos mismos en que se aprende a hablar y luego se cont núa a lo largo de toda la vida. Las razones por las cuales los hi blantes observan su lenguaje suelen ser variadas, pero en la ed $c$ adulta una de ellas se destaca prominentemente: la correccić lingüística, o sea la comparación con la norma loquenditi. Ahol bien, el crítico del Mensajero Argentino se ha colocado en esta pos ción de observador, no de hablante ingenuo de su lengua. Vea mos lo que dice en el párrafo previo al que dedica a la $l l$ :

Por supuesto que no hay casi actor ni actriz que conozca y prac que la diferencia de pronunciación que hay de la $c$ y de la $z$ a s. Este defecto es tan común en el país que quizá esta misma generalidadimf da que se note [...] Pero es preciso que sepan nuestros descendient de Tespis que los teatros de las naciones civilizadas de hoy son escuela, y a veces la norma, de la pura pronunciación nacional ${ }^{4}$

El seseo era, por supuesto, general en la Argentina y en América toda, y a pesar de que "quizá esta misma generalide impida que se note", el autor del artículo lo percibió. ¿Cómo podido hacerlo? Porque se ha dedicado a reflexionar sobre su les guaje, y esto lo hizo guiado por el deseo de ajustar su habla naci nal a la norma del español general, representada entonces por lengua culta de España. Es que un hablante conoce varios si

41 Y la comparación, o sea la conciencia de la lengua, está lejos de red cirse a los rasgos distintivos. U. Weinreich et al., "Empirical Found tions... ", p. 131, señalan acertadamente que los hablantes pueden discutir cr vivacidad variaciones fonéticas de su lengua, en tanto que se muestran indil rentes a cambios fonológicos.

42 Apud Á. Rosenblat, Las generaciones argentinas, p. 12, n. 7 (las cursiv son mías). 
temas lingüísticos, no uno solo, y puede darse cuenta de un rasgo propio de su habla, aunque sea general, por comparación con el habla de sus vecinos o con la lengua estándar. Por esto, la mención del yeísmo rehilado porteño (la "pronunciación viciosísima" de chchch por $l l$ ) de ningún modo obliga a concluir que no debía ser general. Más bien, aquello que en verdad muestra esta mención es que lo único que coexistía en Buenos Aires con el yeísmo rehilado era la idea de que la distinción $l l \cdot y$ constituía la pronunciación correcta.

\section{LAS GRAFÍAS E YO DE ROSAS}

Ya hemos visto que Rosenblat argumentaba que Rosas debía haber carecido de rehilamiento porque escribía $i$ por $y$. La señora de Weinberg consideraba que esta tesis de Rosenblat resulta confirmada por un hallazgo suyo. Siguiendo la misma línea del llorado estudioso de conjeturar directamente los sonidos a partir de la ortografía, llama la atención sobre unos casos en que Rosas reemplaza la conjunción $y$ por $e$ :

V. e yo nos pronunciemos (26.V.1835)

Eran Manuelita e yo (4.VIII. 1835) ${ }^{43}$

Si bien interpreto, la apreciada lingüista infiere de estos ejemplos que la /y/ de Rosas efectivamente no habría debido sonar [z], pues de haber tenido rehilamiento no hubiera sido necesario mudar la conjunción $y$ en $e$. Pero ya se vio que las grafías de $i$ por $y$ en que se fundaba Rosenblat carecían de valor fonético y no hay razonamiento humano o divino que las pueda confirmar. Por ello, el escribir $e$ yo no puede constituir una prueba de que la $\tan$ zarandeada / $/$ / de Rosas careciera de rehilamiento. Para plantear adecuadamente la cuestión, recordemos que en las regiones con una $y$ sin rehilamiento los hablantes no la tratan como la vocal $i$; así, por ejemplo, un hombre puede hablar en Madrid de "su mujer $e$ hijos", pero al Rey de España, al referirse conjuntamente a él y a su esposa, se lo escuchará pronunciar: "la Reina y yo". Este tipo de pronunciación es el que registró don

43 Cf. de María Beatriz Fontanella de Weinberg, "El yeísmo bonaerense", p. 89, y "Un nuevo aporte", p. 271. 
Tomás Navarro Tomás en su Manual al transcribir "y ya llegó como [iyá legó] ${ }^{44}$.

Se ve, pues, que si Rosas hubiera tenido un yeísmo simple no habría habido ningún inconveniente en que escribiera $y y$ Para el uso de $e$ yo no existe, en consecuencia, una razón fonétic y el motivo de esta grafía ha de ser meramente ortográfico. Cies tamente, Rosas no ha de haber escuchado una pronunciación yo. La construcción que usan sus coetáneos, según la documenta ción que he manejado, es siempre y yo $0^{45}$. Que en $e$ yo nos encor tramos ante una pura regla ortográfica queda mostrado porqu ni el mismo Rosas la obedece muchas veces: en sus cartas tan bién y yo está ampliamente atestiguado; en los textos que yo $\mathrm{h}$ visto he encontrado el mismo número de y yo que de $e$ yo: onc para cada uno $^{46}$; añádase que, sin excepción, escribe y $y a^{4}$ Tanto y yo como y ya son las formas únicas de los poemá gauchescos, de modo que, en la medida en que podemos confic que estas obras representan el habla de los gauchos, hay que per sar que eran las pronunciaciones populares. En consecuencia, , cuadro que en este punto presenta la ortografía de Rosas es qu alterna la forma tradicional y corriente $y$ yo con $e$ yo. En este dob] uso no hay prácticamente diferencia cronológica; los ejemplos $\dot{c}$ y yo se escalonan de 1832 a 1869, y los de e yo de 1833 a 1869 (véi se la nota 46). Más aún, en un mismo día alterna las dos forma: en la noche del 26 de agosto de 1833 escribe y yo a Felipe Aran

${ }^{44}$ Manual de pronunciación española, C.S.I.C., Instituto Miguel de Ce vantes, Madrid, 1974, p. 29712. Esta variación en el tratamiento de conjunción y ya fue señalada por Bello en su Gramática de la lengua castellan núm. 1283: "Vuélvese $e$ antes de la vocal $i$, como en españoles $e$ italiano pero no antes del diptongo ie, ni antes de la consonante $y$ : corta y hiere, y yo".

45 Véase en Celesia, Rosas, los casos de y yo o y ya en cartas de 1833 c Juan Ramón Balcarce (p. 383), Prudencio Rosas (pp. 485, 486, 487 [bis 491 [ter], 492 [ter]), Felipe Arana (pp. 398, 399, 403, 404, 428), Manuel I Maza (pp. 439, 444), Vicente González (pp. 449, 458, 459, 460, 471, 4 \& [bis]) y Manuel A. Pueyrredón (pp. 499, 500 [bis], 502 [ter]). En Celess. II, aparece $y$ yo en una carta de 4.1.1834 de Agustín J. Wright (p. 392) y $\mathrm{\epsilon}$ otra de 6.VII.1839 de Bernardo Echeverría (p. 465).

${ }^{46}$ Los ejemplos de y yo en Historia de la Nación Argentina, VII/2, p. ‘ (bis); Celesia, Rosas, pp. 415, 416, 493 (ter), 494 (bis); Raed, Cartas Rosas-Roxas y Patrón, p. 208; Cartas a Josefa Gómez, p. 74 (aquí escribe $i$, no y Los casos de $e$ yo en Celesia, Rosas, p. 464; Rosas, II, pp. 415, 467, 514, 53 RaED, Cartas de Rosas-Roxas y Patrón, p. 209; Cartas a Josefa Gómez, pp. 54, 9 105, 118, 119.

${ }^{47}$ Celesia, Rosas, p. 494; Raed, Cartas a Josefa Gómez, pp. 119, 126. 
y e yo a Vicente Gronzález ${ }^{48}$. Inclusive en una misma carta puede usar las dos formas; así en la del 2 de mayo de 1869 a Josefa Gómez aparecen un $y$ ya y $\operatorname{dos} e y o^{49}$ (a $y$ ya me refiero en especial al fin de este apartado).

¿Por qué Rosas, que usa frecuentemente la forma y yo, forjó la regla de escribir $e$ yo, que a menudo dejaba de aplicar? No existe una investigación de la ortografía de Rosas ni de la de su época, de modo que no resulta posible responder adecuadamente a esta pregunta; en lo que sigue, me limitaré a indicar sólo cómo podría plantearse el problema. La grafía $e$ yo pertenece evidentemente al tema de cómo escribir la conjunción $y$ ante la palabra que empieza con $i$. Sabido es que en el Siglo de Oro se usaba sin empacho $y$ ante $i$-; la regla de cambiarla en $e$ en estos casos parece haberse impuesto en el siglo xviII en la lengua escrita, aunque no en el habla popular ${ }^{50}$. En los textos de Rosas examinados por mí se aplica rigurosamente esta regla, lo mismo que la otra, en cierta manera análoga, de escribir $u$ la conjunción disyuntiva sólo ante $o^{-}$. También en los documentos de coetáneos de Rosas que he leído dominan estas reglas, aunque algunas infracciones he observado: "y invadir" en Felipe Arana ${ }^{51}$, "i ygualm ${ }^{\text {te" }}$ en Facundo Quiroga (1790-1835) ${ }^{52}$, "impresos u algunas comunicaciones" en Vicente González"53, "dejar mis hijos u a la compañera más fina" en Javier López (¿ ?-1836) ${ }^{54}$. Podría ser, pues, que la gente nacida en el Río de la Plata hacia finales del siglo XVIII hubiera aprendido el cambio de $y$ en $e$ ante $i$ - (y de $u$ en $o$ ) como una norma de escribir pulido, que no correspondía a la ortografía que originariamente se les había enseñado.

En este marco histórico hay que colocar la singular grafía $e$ yo; aparece en el momento en que todavía es reciente el triunfo de la regla $y>e$ ante $i$ - y aún no ha desaparecido totalmente el

${ }^{48}$ Cf. Celesia, Rosas, pp. 415, 416 y 464.

${ }^{49}$ Cf. RaED, Cartas a Josefa Gómez, pp. 118 y 119.

${ }^{50}$ Para la historia de la cuestión, véase Ángel Rosenblat, "Notas de morfología dialectal", en $B D H$, t. 2, pp. 181-182.

${ }^{51}$ Celesia, Rosas, p. 419. En otras dos ocasiones Arana usa $e$ : "e introducir" (p. 424) y "e Irigoyen" (p. 427).

52 Enrigue M. Barba, Correspondencia entre Rosas y Quiroga, Universidad Nacional de La Plata, La Plata, 1945, p. 41. Mi cita pertenece a una carta del 4 de diciembre de 1831; en otra del 26 del mismo mes y año escribe "e ygualmente" (p. 49).

${ }^{53}$ Celesia, Rosas, p. 470. En otros once casos González usa 0.

${ }^{54}$ Carta del 10 de enero de 1836, apud ElENA M. RoJas, Evolución histórica del español en Tucumán, p. 255. 
viejo uso de mantener inalterable la conjunción $y$. Se trata, pues de una situación de convivencia de normas, terreno fértil par que aparezcan ultracorrecciones, y $e$ yo pudiera ser algo así com una ultracorrección ortográfica. Rosas habría extendido a la con junción $y$ ante $y$ - el trato propio que tenía ante $i$-; recuérdese qu en su época $y$ era, con mayor amplitud que en la actualidad, un de las grafías de /i/, de modo que lo que estaría haciendo Rosa sería generalizar un mismo tratamiento para las dos letras de est fonema. Con todo, este argumento daría razón del uso de $e$ cuan do la $y$ tiene valor vocálico, por ejemplo en "e Yndios" (no h encontrado casos en que la conjunción copulativa preceda a $Y$-, pero no explicaría un caso como e yo, en que Rosas está ignoran do el carácter consonántico de $y$. Este punto permanece oscur para mí. Acaso valga la pena señalar que el cambio de y a $e$ l hace Rosas sólo ante la palabra yo; de la construcción y ya he re cogido tres ejemplos (cf. la nota 47) y en todos se conserva la (no he hallado instancias de $y$ seguida de otras palabras con $y$ con sonante inicial que no fueran yo y ya). Si se reúnen más casos e que siempre se mantiene la y ante ya, podría pensarse que Rosa está realizando una especialización léxica de la ortografía, com vimos que había hecho reservando la $i$ para suio, cuio, vaia y algu nas otras voces, mientras las otras formas que tenían /y/las escri bía con $y$; el tratamiento de la conjunción $y$ ante $y$-consonant como si fuera $y$-vocal estaría reservado para la palabra yo. Si est fuera el caso, también aquí se me escaparía el motivo de tal con ducta. Pero, para lo que ahora discutimos, no nos interesa má que mostrar que la aislada grafía e yo sólo revelará su significad estudiándola dentro del problema ortográfico del que es manifes tación enigmática.

\section{LA FORMA BÁHIA POR BAHÍA}

Pasamos a la tercera prueba que presenta la señora de Weinber en favor de la existencia de la y simple. Se encuentra en una pág: na del abogado y periodista porteño Adolfo Lamarque (185: 1888). En un artículo de 1885 refiere un viaje a Bahía Blanca hace estas observaciones sobre el nombre de la ciudad:

La gente vulgar la llama Badía; la gente ilustrada, cuando pronur eia el nombre completo, Báhia Blanca; lo que se aproxima a $B a$; Blanca. Esto nos preocupa y nos alarma. Mañana o pasado, figi 
rense ustedes, va por allí un explorador; oye decir Baya Blanca, y esa misma noche, en el silencio de su gabinete... después de valerosas inducciones, se penetra de la existencia de una planta con bayas blancas;... entonces nuestro explorador desolado, busca puntos de contacto con la Sierra Bay $a^{55}$.

Según se ve, Lamarque nos informa que la "gente decente" de esta ciudad del sur de la provincia de Buenos Aires pronunciaba Báhia la primera palabra de su nombre, con la dislocación dél acento consiguiente a la desaparición del hiato entre la primera $a$ y la $i$. He aquí la interpretación del pasaje que hizo la señora de Weinberg. Comienza por decirnos que la pronunciación Báhia que escuchó Lamarque era fonéticamente [báia]. Luego destaca el siguiente punto de la noticia del periodista porteño:

Lo que aquí nos interesa especialmente es la afirmación de que "[báia] Blanca... se aproxima a Baya Blanca" y los siguientes juegos de palabras que muestran la posibilidad de confusión de [báia] con baya 'tipo de fruto' y con baya 'de color blanco amarillento'56.

Sobre esta base discurre su razonamiento. Como Báhia [báia] estaba próxima a Baya, según dice Lamarque y lo confirma la posibilidad de confusiones entre las dos palabras, resulta evidente para la señora de Weinberg que Baya no había de tener [ž ; éste es un sonido muy distinto de [i] y con él nunca habría habido confusiones. Para que éstas se produjeran, la y de Baya debía ser una $y$ consonante sin rehilamiento, cuanto más con un breve rehilamiento inicial: [ $\left.{ }^{z} y\right]$. El pasaje de Lamarque queda así convertido en otra prueba de la existencia de una [y] porteña ${ }^{57}$.

De nuevo me veo forzado a discrepar con la señora de Weinberg. En cuanto al valor del sonido palatal de Báhia, éste ha debido ser [y] (por lo menos; cf. el punto $c$ al final de este apartado). Al desaparecer el hiato y producirse la dislocación del acento, la $i$ se consonantiza; por ejemplo, cuando en las terminaciones del imperfecto se produce la sinéresis y se traslada el acento a la vocal más abierta: -eía > -éia, surgen formas con y consonante como leia > léia [léya], creía > créia [kréya], etc. ${ }^{58}$. De modo que lo

55 "Un nuevo aporte", p. 272.

56 Ibid., p. 273.

57 Loc. cit.

58 Véase Amado Alonso, "Cambios acentuales", en sus Problemas de 
que habría escuchado Lamarque en boca de los bahienses ilustri dos sería [báya].

También debo apartarme de la destacada investigadora en $\varepsilon$ interpretación del pasaje de Lamarque. Como se ha visto en trozo suyo poco más arriba copiado, se funda para su tesis en qu Lamarque dice que Báhia ([báya], según yo propongo) "se apr xima" a Baya y que esto producía confusiones entre las dos pali bras. Ahora bien, en la frase casi inmediatamente siguiente aquella en que aparece el "se aproxima", Lamarque escrib، "Mañana o pasado [...] va por allí [por Bahía Blanca] un expl. rador; oye decir Baya Blanca [...]'; aquí Baya Blanca es igual Báhia, porque representa la forma con que los bahienses pronur cian el nombre de su ciudad. Vendría a resultar, pues, que $B a j$ es la representación más "fonetizada" de lo que primero hab: escrito Báhia. Por lo tanto, en el pasaje de Lamarque habría dc versiones de la relación sonora entre Báhia y Baya: 1) semejanz: Báhia "se aproxima" a Baya; 2) equivalencia: en Bahía Blanc se "oye decir Baya Blanca". Puede verse que el texto de Lama que no es claro y esto es inherente a su carácter periodístico, qu le hace carecer del rigor conceptual y del lenguaje técnico qu evitarían confusiones u oscuridades como la que acabamos c descubrir. Siendo ésta la situación, con respecto a su noticia st bre la /y/ no podemos salir del terreno de las conjeturas, ningur de las cuales llega a ser satisfactoria por una u otra razón. Mer cionaré a continuación algunas de las que se pueden hacer.

A mí me parece que el verdadero pensamiento de Lamarqu es que existe la equivalencia entre Báhia y Baya; esto lo dice expl citamente y, a menos que le achaquemos incoherencia menta hay que suponer que no está en contradicción con el "se aprox ma" anterior; también las confusiones a que se refiere se expl can mejor por una igualdad que por un mero parecido. Basánd nos en estas consideraciones, pasemos a título de hipótesis qu ha usado el "se aproxima" en forma imprecisa o impropia, corr 'hacerse próximo a algo hasta confundirse con él, pasar a si idéntico con algo'; no por esto, sin embargo, logra mayor ciar dad el pasaje. El partir de la equivalencia Báhia = Baya abre de posibilidades de interpretación, cada una de las cuales lleva a u callejón sin salida:

1) Dado que Báhia era [báya], cuando Lamarque presenta pronunciación de Báhia Blanca como Baya Blanca estaría represer

dialectología hispanoamericana, en $B D H$, t. 1, p. 330 , n. 1. 
tando con $y$ una $[y]$, o sea que ni él ni los bahienses tendrían una $y$ rehilada. De más está decir que después de todas las pruebas de la generalidad del yeísmo rehilado que he reunido más arriba, no me hallo dispuesto a dudar de que existiera mientras no aparezcan datos más sólidos que una conjetura basada en un texto poco claro.

2) Si se acepta, en cambio, que Baya era [báža], resultaría que Báhia se pronunciaría con [žz]. Pero ocurre que el rehilamiento de la [y] resultante de la dislocación del acento por desaparición de un hiato no está atestiguado, que yo sepa, en la Argentina (cf. la nota 58). Como no me parece posible pensar que Baya no fuera [báža], podemos seguir alguna de las siguientes pistas para salir del laberinto:

a) El periodista se equivocó al dar la equivalencia. Ésta es, desde luego, la lectio facilior (por decirlo así) del problema, y resulta difícil de aceptar dada la manera expresa en que dice que en Bahía Blanca se "oye decir Baya Blanca".

b) Podemos adoptar al pie de la letra la primera relación que da Lamarque como que Báhia [báya] únicamente "se aproxima" a Baya. Ahora, si la [y] de Báhia sólo se parece al sonido palatal de Baya, siendo sin embargo distinto de él, ¿qué otra cosa puede ser éste sino [ž]? Así, el sonido procedente de la dislocación del acento puede ser [y] y el de Baya corresponder a [ž]. Ésta sería la solución ideal, pero se logra al precio de ignorar la equivalencia entre Báhia y Baya que el periodista establece a renglón seguido. Con ella no resolvemos el problema de las dos relaciones que presenta el texto, sino lo eludimos eligiendo arbitrariamente como verdadera una de ellas. Pero no se trata de fabricar una solución a todo trance, sino de explicar un problema: ¿qué ha querido decir Lamarque?

c) La incapacidad de descubrirlo bien puede deberse a mi insignificante persona. Pero también puede ser que nos falte una pieza de este rompecabezas. El español de América es tan mal conocido que resulta poco prudente querer sacar conclusiones absolutas sobre los datos hoy accesibles. Como expresé en el punto 2), no he aceptado que la equivalencia Báhia = Baya fuera [báža] porque no hay testimonios de que se rehile la $[y]$ procedente de una dislocación acentual. Mi fuente en este punto fue un trabajo de Amado Alonso del año 1930, cuando hacía apenas tres años que había llegado a Buenos Aires. Poco desarrollada estaba por aquel tiempo la dialectología hispanoamericana. ¿Puede hoy sostenerse igualmente que no hay rehilamiento en estos casos? Digo 
esto porque en el último curso que hace ya treinta años dicté la Universidad Nacional del Sur, sita en Bahía Blanca, uno mis estudiantes me afirmó con mucha seguridad que existía $u$ : pronunciación [bazénse] del gentilicio bahiense. El tiempo ha $\mathrm{k}$ rrado de mi memoria las indicaciones que me dio al respect ¿Existe o existió una pronunciación Báhia [báža], que podría s aquella que escuchó Lamarque y que representó como Báhia Baya?

En suma, hoy por hoy no estamos en condiciones de sak qué quiso decir Lamarque al escribir que la pronunciación $B a ́ i$ era semejante / igual a Baya. Su testimonio no puede servir cor prueba de la existencia de [y], ni tampoco de la de [̌̌]. Simp. mente, es oscuro.

\section{Mirada Retrospectiva}

Tras los prolijos exámenes precedentes no me resulta posil aceptar que en el siglo xix se dio en Buenos Aires una variaci lingüística entre $[y]$ y [ž]. Me ha sido forzoso partir compar con la señora de Weinberg en este punto, pues no creo que la c cumentación alegada apoye la existencia de [y]; por el contrar en mi opinión todos los datos apuntan a que la forma rehila dominaba como única. Ha sido inevitable que la tesis de la var ción de $[y]$ y [ž fuera un espejismo, porque la supuesta exist $\epsilon$ cia de [y] tiene su punto de partida en unas notas de lectura Ángel Rosenblat, que por circunstancias de su vida no llegć completar y estudiar en profundidad; aunque este aspecto huma del caso compromete nuestra simpatía, no puede hacernos ol dar que un estudio histórico que no se base en una reconstrı ción tan amplia y sistemática como sea posible y en un cono miento de la situación cultural de la época, fatalmente termim tomando lo ocasional por lo general o ignorará el significado ؛ nuino de los hechos que trata. Pero Rosenblat nos ha dejado t: bajos fundamentales sobre el español de América; de ellos $r$ beneficiamos todos y junto a ellos es minúsculo lapso la malhac da ocurrencia de que Rosas tenía una y sin rehilamiento. Enter. mos esta idea de una vez para siempre en homenaje a su memor

Guillermo L. GuitaF Boston Coll 